\title{
DEVELOPMENT OF CARRAGEENAN HYDROGEL AS A SUSTAINED RELEASE MATRIX CONTAINING TOCOTRIENOL-RICH PALM-BASED VITAMIN E
}

\author{
CHEONG MEI YEE*; ZAFARIZAL ALDRIN AZIZUL HASAN*; NORASHIKIN AHMAD* \\ and HAZIMAH, A H *
}

\begin{abstract}
Topically applied hydrogel system as a general therapeutic mask for transdermal delivery of hydrophobic actives is not efficient due to the differences in polarity between the actives and the polymer network. This work presents a study on developing hydrogels based on carrageenan as a matrix for the delivery of a hydrophobic type of active, i.e. tocotrienol-rich palm-based vitamin $E$ (TRPE) into the skin. The strength and flexibility of the hydrogel were increased by the inclusion of guar gum, potassium citrate and glycerine. The thermogravimetric analysis (TGA) results indicated a higher quantity of water in the hydrogel with glycerine while differential scanning calorimetry (DSC) showed three types of water molecules existed in the hydrogel. The hydrogel was non-irritating according to OECD Test Guideline No. 439 for in vitro skin irritation test. The hydrogel with TRPE fluids was able to permeate the polysulfone membrane and bioavailability of TRPE improved with the inclusion of PEG-40 hydrogenated castor oil mixture. Therefore, a carrageenan-based hydrogel with locust bean, guar gum, glycerine, potassium citrate and TRPE was successfully developed with good strength and flexibility and without any potential irritancy. The good bioavailability of TRPE-loaded in the hydrogel can be used for skin care application.
\end{abstract}

Keywords: tocotrienol-rich palm vitamin E, carrageenan, hydrogel.

Date received: 8 January 2016; Sent for revision: 20 January 2016; Received in final form: 27 July 2016; Accepted: 28 July 2016.

\section{INTRODUCTION}

The skin is composed of the epidermis, dermis and subcutaneous tissue with the epidermis consists mainly of keratinocytes (Kilpatrick-Liverman et al., 2009). The keratinocytes surface has the potential to be a medium allowing direct diffusion of supplement from hydrogel. As skin is the largest organ of the human body, it could be a site for supplement

\footnotetext{
Malaysian Palm Oil Board,

6 Persiaran Institusi Bandar Baru Bangi, 43000 Kajang,

Selangor, Malaysia.

E-mail: cheongmy@mpob.gov.my
}

delivery due to ease of application. Water-cast gels are used as facial masks or adhesive skin patches with the ability to adhere to the keratinous surface that will impart water retention, hydration, regulation of skin temperature and delivery of the active ingredients to the epidermis (Tsujihata, 2010).

Hydrogels are synthetic and/or natural polymers that can absorb and retain significant amount of water to form three-dimensional network structures. The cross-linked polymeric network that forms when hydrated is due to the hydrophilic group present in the hydrogel structure (Rosiak and Yoshii, 1999). The ionisable functional groups which promote the hydration of hydrogels, affect the 
properties such as biocompatibility, permeability and mechanical stability (Kim et al., 2001). The gel matrix network is porous, enabling drugs or actives to be loaded, held and subsequently released. The rate of release is dependent on the diffusion coefficient of the drug or actives through the gel network (Deepa et al., 2012). Hydrogels have low interfacial free energy when their hydrophilic surface comes in contact with body fluids, hence, good biocompatibility with skin. The hydrogel also minimises irritation to the surrounding tissue from its soft and rubbery texture (Anderson and Langone, 1999; Smetana, 1993).

Tocotrienol-rich palm-based vitamin E (TRPE) is used as a functional ingredient in cosmetics products for its role in protecting the skin from free radical damage induced by the ultraviolet radiation (Zafarizal et al., 2008). However, hydrogel systems for hydrophobic actives like TRPE are rarely reported due to the differences in polarity or incompatibility of the hydrophilic polymer network and hydrophobic drug. This problem can be solved by preparing a semi-interpenetrating networks and incorporating surfactant to encourage the formation of oil-in-water $(\mathrm{O} / \mathrm{W})$ emulsion to entrap the hydrophobic actives in the network. In order to achieve optimum bioavailability, solubility and efficacy in supplementing the actives, there is a need to alter the hydrogel properties such as solubility and bioadhesivity.

A gel's structure, hardness, elasticity and stickiness are attributed to the cross-linking behaviour between the polymers chains which resulted in viscoelastic and sometimes pure elastic behaviour (Gulrez et al., 2011). Therefore, polysaccharide blends are used to form synergistic gels due to their good biodegradability and better physico-chemical properties. Fernandes et al. (1991) reported that locust bean gum (LBG) and kappacarrageenan blends are popular and have found numerous applications in the food industries. LBG is known for its excellent synergism with carrageenan to form elastic, strong, low syneresis and thermoreversible gels (Rees, 1969; Dea and Morrisson, 1975). Carrageenan, a naturally occurring high molecular weight sulphated polysaccharide is derived from red seaweed, Rhodophyceae (Imeson, 2000). The LBG contributed to the bioadhesive properties of a hydrogel by providing several sites for hydrogen bonding (Farnoosh et al., 2011). Gels are formed when the repeating helical structure of carrageenan dimers interact with the unsubstituted or mannose-free regions of the LBG. At ratios between 60:40 and 40:60 of kappa carrageenan to LBG, there is a maximum bonding which resulted in gel strength, rigidity and cohesiveness (Imeson, 2000). LBG and guar gum (GG), on the other hand, are categorised as galactomannan polysaccarides which consist of a 1, 6- $\alpha$-D-galactose side chains and 1,4- $\beta$-D-mannose backbone. The difference between GG and LBG is that the former is richer in D-galactose groups (1:2) than the latter (1:4). GG with numerous hydroxyl groups, straight chain structure of galactomannan and along with the regularity of the single membered galactose branches result in a product that exhibits an excellent compatibility on other hydrocolloids systems through hydrogen bonding activity (Chudzikowski, 1971). The number of hydrogen bonding sites affects the bioadhesivity of a hydrogel which attract other functional groups such as glycoprotein on the surface of stratum corneum (Farnoosh et al., 2011; Kilpatrick-Liverman et al., 2009).

While there are a number of patents for producing gel sheet for cosmetics purposes, none described the incorporation of hydrophobic actives into the hydrophilic gel network or substantiate the claims on permeation of actives into the keratinocytes. Therefore, this study reports the development and characterisation of bioadhesive hydrophilic gel sheet with hydrophobic TRPE for transdermal delivery. The gels were characterised using texture analyser (TA), differential scanning calorimetry (DSC), thermogravimetric analysis (TGA) and permeation analysis using vertical diffusion cell. Although the tocotrienol-rich fraction from palm oil was reported not to induce any cutaneous irritation or sensitisation by Zafarizal et al. in 2008, the EpiSkin ${ }^{\mathrm{TM}}$ skin irritation test was conducted to ascertain the safety of skin when hydrogel laden with TRPE was utilised. The permeation liquid was sent for nanoparticle size analyser and transmission electron microscopy (TEM) to determine the particle size of the TRPE that permeated the membrane.

\section{MATERIALS AND METHODS}

\section{Materials}

Carrageenan (Genugel ${ }^{\circledR}$ CG-130) from CP Kelco was kindly donated by Brenntag Specialites Inc. (Germany). LBG from Ceratonia siliqua seeds and GG were obtained from Sigma Life Science (USA). PEG-40 hydrogenated castor oil with the trade name Solubilisant Gamma 2428 was bought from Gattefossé s.a. (France), while phenoxyethanol and ethylhexylglycerin (Euxyl PE ${ }^{\circledR}$ 9010) were bought from Schulke \& Mayr GmbH (Germany). U.S.P. food grade potassium citrate was bought from Mallinckrodt Plc (Ireland), while glycerine (Pricerine $^{\mathrm{TM}}$ 9091) was sourced from Croda International Plc (United Kingdom). The TRPE (Gold Tri $\mathrm{E}^{\mathrm{TM}}$ ) was purchased locally from Sime Darby Foods and Beverages Marketing Sdn Bhd (Malaysia). The tocopherol and tocotrienol content in the palm oil derived vitamin $\mathrm{E}$ is $563.0 \mathrm{mg} \mathrm{g}^{-1}$ 
whereby the total tocotrienol content is $425.6 \mathrm{mg}$ $\mathrm{g}^{-1}$. The specific contents are: $\mathrm{d}-\alpha$-tocopherol: 137.4 $\mathrm{mg} \mathrm{g}^{-1}, \mathrm{~d}-\alpha$-tocotrienol: $148.5 \mathrm{mg} \mathrm{g}^{-1}, \mathrm{~d}-\beta$-tocotrienol: $20.9 \mathrm{mg} \mathrm{g}^{-1}, \mathrm{~d}-\gamma$-tocotrienol: $189.1 \mathrm{mg} \mathrm{g}^{-1}$ and $\mathrm{d}-\delta$ tocotrienol: $67.1 \mathrm{mg} \mathrm{g}^{-1}$.

Episkin $^{\mathrm{TM}}$ model was sourced from SkinEthnics $^{\mathrm{TM}}$ Laboratories (Lyon, France). Sodium lauryl sulphate (SLS; purity >99\%) and 3-[4, 5-Dimethyl thiazol-2-yl]-2, 5-diphenyl tetrazolium bromide (MTT) were purchased from SigmaAldrich (St Louis, USA).

Experiments with the vertical diffusion cell were performed using isotonic phosphate buffered saline (PBS) solution, $\mathrm{pH} 7.4$, containing $8.00 \mathrm{~g} \mathrm{NaCl}$, $0.20 \mathrm{~g} \mathrm{KCl}, 0.20 \mathrm{~g} \mathrm{KH}_{2} \mathrm{PO}_{4}$ and $1.44 \mathrm{~g} \mathrm{Na}_{2} \mathrm{HPO}_{4} \cdot 2 \mathrm{H}_{2} \mathrm{O}$ in 1 litre distilled water. All the buffer salts were sourced from Merck GmbH (Germany).

Table 1 showed the general formulation of the gel. Carrageenan, LBG and GG were first premixed with glycerine before being dispersed in deionised water at room temperature, $25^{\circ} \mathrm{C}$. Then, the mixture was stirred and heated to $80^{\circ} \mathrm{C}$ until a uniform gel was obtained. The gum dispersion carry out different experiments. The characteristics of a flawless gel sheet were evaluated based on homogeneity, transparency, absence of air bubbles, plasticity and uniform thickness.

\section{Characterisation}

Texture analysis. The tensile properties of the gels such as strength and elongation at break were tested using a TA model Ta.xt.plus from Stable Micro Systems, United Kingdom. The type of probe used was SMS P/55, while the gel was fixed on film support rig model HDP/FSR. The settings used were $100.0 \mathrm{~g}$ for force, $20.0 \mathrm{~mm}$ for distance, 2.0 $\mathrm{mm} \mathrm{s}^{-1}$ for test speed and $1.0 \mathrm{~g}$ for trigger force. The thickness of the gel ranging from $0.9 \mathrm{~mm}$ to $1.5 \mathrm{~mm}$ was determined by a micrometer screw gauge in three different areas of each sample.

Thermogravimetric analysis (TGA). The amount of residual water; the glycerine content and its effect on the gels were determined by TGA. About $10-15$ mg of sample was weighed and placed in alumina

TABLE 1. GENERAL FORMULATION OF GEL

\begin{tabular}{|c|c|c|c|}
\hline Phases & $\begin{array}{l}\text { Ingredient commercial } \\
\text { name }\end{array}$ & $\begin{array}{c}\text { International nomenclature of cosmetic } \\
\text { ingredients (INCI) name }\end{array}$ & $\begin{array}{c}\text { Quantities } \\
(\%)\end{array}$ \\
\hline \multirow[t]{5}{*}{ Phase 1} & - & Aqua & QSP \\
\hline & Pricerine $^{\mathrm{TM}} 9091$ & Glycerine & 3.50 \\
\hline & Genugel CG-130 & Carrageenan & 0.50 \\
\hline & $\begin{array}{l}\text { Locust bean gum from } \\
\text { Ceratonia siliqua seeds }\end{array}$ & Ceratonia siliqua gum & 0.50 \\
\hline & Guar gum & Cyamopsis tetragonoloba gum & 0.25 \\
\hline \multirow[t]{4}{*}{ Phase 2} & Solubilisant Gamma 2428 & $\begin{array}{c}\text { PEG-40 hydrogenated castor oil (and) } \\
\text { polysorbate } 20 \text { (and) octoxynol-12 }\end{array}$ & 5.00 \\
\hline & Potassium citrate & Potassium citrate & 1.00 \\
\hline & Gold Tri E ${ }^{\mathrm{TM}}$ & $\begin{array}{l}\text { d- } \alpha \text {-tocopherol (and) d- } \alpha \text {-tocotrienol (and) } \\
\text { d- } \beta \text {-tocotrienol (and) d- } \gamma \text {-tocotrienol (and) } \\
\text { d- } \delta \text {-tocotrienol }\end{array}$ & 1.00 \\
\hline & Euxyl ${ }^{\circledR}$ PE 9010 & Phenoxyethanol (and) ethylhexylglycerin & 0.5 \\
\hline
\end{tabular}

was homogenised at $10000 \mathrm{rpm}$ for $10 \mathrm{~min}$ to homogenise the residues. The prepared gels were loaded with TRPE and PEG-40 hydrogenated castor oil as solubiliser, potassium citrate, phenoxyethanol and ethylhexylglycerin as preservatives before the mixture was homogenised for another $1 \mathrm{~min}$. It was kept in a water bath, and the temperature was maintained at $70^{\circ} \mathrm{C}$ to facilitate the removal of bubbles. The mixture was poured into polyethylene moulds / trays with the required volumes to give 2-3 $\mathrm{mm}$ thickness gels. Then they were kept for $1 \mathrm{hr}$ at ambient temperature for setting and solidification. These moulds were covered, packed and sealed. Samples were cut into the required sizes in order to pans $(100 \mu \mathrm{l})$. The weight loss was determined using a Simultaneous Thermal Analyser, STA 6000, Perkin Elmer. The experimental programme consisted of heating the samples from $25^{\circ} \mathrm{C}$ to $850^{\circ} \mathrm{C}$ at a heating rate of $10^{\circ} \mathrm{C} \mathrm{min}^{-1}$. Nitrogen at a flow rate $20 \mathrm{ml} \mathrm{min}^{-1}$ was used to ensure an inert atmosphere.

Differential scanning calorimetry (DSC) analysis. The thermal analysis or melting behaviour of the hydrogels and bound water containing various amount of glycerine from 0.05 to $0.6 \mathrm{mM} \mathrm{g}^{-1}$ were observed by using DSC to analyse the effect of glycerine on the gel network. The DSC was performed on model STD 6000, Perkin Elmer. Each 
sample (6.3 to $10.1 \mathrm{mg}$ ) was placed in an aluminium pan with pierced cover, sealed, and its thermogram was acquired by scanning from $30^{\circ} \mathrm{C}$ to $-50^{\circ} \mathrm{C}$ with cooling rate of $10^{\circ} \mathrm{C}$ min, using an empty aluminium pan as reference. The water content of the gels was determined by recording the weight difference between fresh and dried samples in the oven at $60^{\circ} \mathrm{C}$ until the weight remained constant.

Water content, freezing water and non-freezing water were defined as the following equation:

- water content $\left(W_{c}\right)=(g$ of water $) /(g$ of dry sample);

- freezing water $\left.\left(\mathrm{W}_{\mathrm{f}}\right)=\left[\left(\Delta \mathrm{H}_{\mathrm{m}}\right) / 334\right] / \mathrm{m}_{\text {dry sample }}\right)$; and

- non-freezing water $\left(\mathrm{W}_{\mathrm{nf}}\right)=\mathrm{W}_{\mathrm{c}}-\mathrm{W}_{\mathrm{f}}$.

where $\mathrm{m}_{\text {dry sample }}$ is mass of the dried sample. Melting peak entalphy $\left(\Delta \mathrm{H}_{\mathrm{m}}\right)$ was calculated using pure water as a reference material. $W_{f}$ contains both free water and freezing bound water $\left(\mathrm{W}_{\mathrm{fb}}\right)$. Distilled water was used as a reference material with melting peak entalphy of $334 \mathrm{~J} \mathrm{~g}^{-1}$ (Dean, 1973).

EpiSkin ${ }^{T M}$ skin irritation test. A fully differentiated three-dimensional epidermal tissue model, Episkin $^{\mathrm{TM}}$ Reconstructed Human Epidermis (RHE), age day 18, tissue surface: $1.07 \mathrm{~cm}^{2}$, supplied by SkinEthnics ${ }^{\mathrm{TM}}$ Laboratories (Lyon, France) was used. Episkin ${ }^{\mathrm{TM}}$ is an in vitro RHE from normal human keratinocytes which is cultured on a collagen matrix as the supporting system in a chemically defined medium. This model is histologically similar to in vivo human epidermis. As per manufacturer's instruction, the following procedures were performed under sterile airflow. Immediately after arrival, the RHE tissues were removed from the agarose-nutrient solution packed in the multiwall plate during shipping. They were placed in a 24-well plate that were filled with 300 $\mu$ l growth culture medium beforehand. The culture dishes were incubated at $37^{\circ} \mathrm{C}, 95 \%$ humidified atmosphere and $5 \% \mathrm{CO}_{2}$ for $2 \mathrm{hr}$ before conducting the experiments. The tissue samples were transferred into $300 \mu \mathrm{l}$ maintenance medium in a 24 -well plate at the end of the pre-incubation step. Distilled water, $10 \mu \mathrm{l}$ was pipetted to wet the surface of RHE tissue prior to application of sample. Then, the cut-out hydrogel samples with diameter of $5 \mathrm{~mm}$ were placed on RHE tissues so that they could be topically exposed to the gel at room temperature. The reference irritant standard (positive control) used was $16 \mu$ l of sodium dodecyl sulphate (SDS $5 \% \mathrm{w} / \mathrm{v}$ aqueous solution) and $16 \mu \mathrm{l}$ PBS served as the negative control, with both being pipetted onto the epidermis surface respectively. The lids were placed on the plates containing the treated RHE tissues for 42 min exposure in the ventilated cabinet sterile conditions at $25^{\circ} \mathrm{C}$ before they were removed for rinsing. Using a multistep pipette, the sterile PBS was deposited onto RHE tissues for 25 times with $1 \mathrm{ml}$ each time. The treated and rinsed RHE tissues were dried with sterile cotton bud and incubated again at $37^{\circ} \mathrm{C}, 95 \%$ humidified atmosphere, $5 \% \mathrm{CO}_{2}$ for $42 \mathrm{hr}$ after adding in $2 \mathrm{ml}$ growth culture medium. MTT reduction measurement was conducted to assess tissue viability. Each experiment was repeated three times.

MTT assay. The cytotoxicity level was determined by measuring the dehydrogenase activity of viable keratinocytes. The methodology used to monitor cytotoxicity activity was carried out after the inclusion of 3-[4, 5-dimethyl-thiazol-2-yl]-2, 5-diphenyl tetrazolium bromide (MTT, SigmaAldrich). The $1 \mathrm{mg} \mathrm{ml}^{-1}$ MTT solution was pipetted onto the treated RHE tissues and incubated for 3 hr. Isopropanol was then used to extract the blue formazan crystals in a rotating orbital shaker for at least $2 \mathrm{hr}$. A spectrophotometer was used to measure the concentration of formazan via the optical density (OD) at $570 \mathrm{~nm}$. Nine measurements per test substance (three RHE tissues, three replicates / tissue) whereby blank OD values and standard deviations (SD) were obtained. With the negative control value set at $100 \%$, the percentage of cell viability was expressed relative to the negative control as: $100 \times$ mean $\mathrm{OD}_{\text {treated }} /$ mean $\mathrm{OD}_{\text {control }}$. Calculations of the OD values were performed for each test substance, each of it was done on three replicate tissues, respectively.

In vitro TRPE release by absorption. Permeation test on polysulfone membranes (HT-450 Tuffryn ${ }^{\circledR}$, Pall) with pore size of $0.45 \mu \mathrm{m}$ and diameter of 25 $\mathrm{mm}$ were carried out using a vertical diffusion cell system (Hanson Research, Chatsworth CA, USA) consisting of six thermostated cells with the upper receptor chambers and the lower donor separated by a membrane, with the polysulfone membrane facing the donor chamber. The donor compartment diameter was $15 \mathrm{~mm}$, providing an application area of $1.77 \mathrm{~cm}^{2}$. An external water jacket with circulating water kept the temperature of the receptor compartment constant at $37^{\circ} \mathrm{C}$. About $7 \mathrm{ml}$ of PBS filled the receptor compartment which was stirred by a magnetic bar rotating at a constant speed (400 rpm). After $30 \mathrm{~min}$ of temperature equilibration of the receptor solution with the polysulfone membrane, a hydrogel sample of $15 \mathrm{~mm}$ diameter was cut out to cover the membrane surface. Glass slides were used to cover the donor compartment to impede evaporation of the solvent. The sampling was done at pre-determined intervals of time, $(0.0$, $0.5,1.0,1.5,2.0,2.5 \mathrm{hr}$ ), whereby $1.0 \mathrm{ml}$ sample was withdrawn from the receiving phase for UV-VIS (UV-1800 Shimadzu, Japan) analysis at $290 \mathrm{~nm}$. All experiments lasted $2.5 \mathrm{hr}$ and were repeated three 
times. The penetrated levels of TRPE were calculated by dividing the amount of test product found in the PBS receptor by the amount of applied product. The permeation liquid was sent for nanoparticle size analyser and TEM to determine the particle size of the vitamin E emulsion that had permeated through the polysulfone membrane.

Data analysis. The following parameters were derived from plotting pseudo-steady-state diffusion plots and subsequently analysing linear regression. The steady-state flux $(J)=Q /$ A.t where $Q$ is the amount of permeate diffusing across the area $(A)$ in time $(t)$. The $x$-axis intercept values of the regression lines with TRPE amount permeate at end of the experiment $\left(Q_{60 \text { min }}\right)$ give the time taken by the TRPE to saturate the membrane and to reach the receiving phase. The TRPE apparent diffusion coefficient through membrane $\left(D_{m}\right)=h^{2} / 6 t_{L}$, where $h$ is the thickness of the polysulfone membrane that was used, $145 \mu \mathrm{m}$, as obtained from the product specification and $t$ the lag time. The permeability coefficient, $\left(K_{p}\right)=J / C_{o}$ whereby $J$ is the flux at steady state $\left(\mu \mathrm{g} \mathrm{cm} \mathrm{cmin}^{-1}\right.$ ) and $C_{o}$ is the initial TRPE concentration $\left(\mu \mathrm{g} \mathrm{cm}^{-3}\right)$. From the relationship, $K_{p}=K_{m} D_{m} / h$, membrane / vehicle partition coefficient, $\mathrm{K}_{\mathrm{m}^{\prime}}$ was derived (Monti et al., 2015).

Transmission electron microscopy (TEM). TEM characterised the microstructure of the diffused vitamin E. The structure and morphology of TRPE globules were viewed under TEM Hitachi H-7100.

Particle size analyser. The particle size distribution and polydispersity index of the microemulsion were measured using a dynamic light scattering (DLS) technique using a high performance particle sizer (Malvern Instruments, HPP 5001, UK). Sample were collected from vertical diffusion cell system and the sample amount was diluted five times with distilled water before being analysed at $25^{\circ} \mathrm{C}$.

Statistical analysis. Data are the average of three determinations with SD. Analysis of variance (ANOVA) was accompanied with a Tukey test (IBM SPSS Statistics 20, IBM Corp., USA). Differences between groups and samples were considered statistically significant at $95 \%$ confidence intervals or $\mathrm{P}<0.05$.

The ingredients studied. The inclusion of glycerine, GG, potassium citrate and PEG-40 hydrogenated castor oil mixture was investigated. Glycerine, guar gum and potassium citrate affected the strength and elongation at break as measured by a texture analyser (Ta.xt.plus, Stable Micro Systems, UK). Glycerine was the major factor impacting the quantity of the secondary bound water as measured by TGA and DSC. PEG-40 hydrogenated castor oil mixture was the factor affecting the permeation of TRPE. The ranges of the ingredients were chosen based on the amount enough to produce a firm gel but without compromising on the strength and rigidity of the gels. The amount studied were carrageenan, $0.2 \%$ $0.5 \%(\mathrm{w} / \mathrm{w})$; locust bean gum, $0.2 \%-0.5 \%$ (w/w); guar gum, $0.0 \%-0.5 \%(\mathrm{w} / \mathrm{w})$; glycerine, $0-0.6 \mathrm{mM}$ $\mathrm{g}^{-1}$; potassium citrate, $0-0.65 \mathrm{mM} \mathrm{g}^{-1}$ and PEG-40 hydrogenated castor oil, $0 \%-5 \%(\mathrm{w} / \mathrm{w})$.

\section{RESULTS AND DISCUSSION}

The stages in the formulation of the gels entailed hydration to swell the polymer and setting in order to produce a thin film. Carrageenan alone formed a firm but brittle gel. A firm and flexible gel was produced when carrageenan was used in the presence of LBG and glycerine as plasticiser. The production of a homogenous gel by complete hydration was time-consuming due to its temperature dependent process and high molecular weight. A complete swelling at room temperature, $25^{\circ} \mathrm{C}$ can be achieved by prolonging the hydration of carrageenan in aqueous solution for $24 \mathrm{hr}$.

The film was rated based on a number of criteria such as uniform thickness, high transparency, homogeneity, flawless condition without any entrapped air bubbles or oily patches, strength and flexibility (plasticity).

The physical properties such as tensile strength and elongation at break were quantified using the TA. The characterisation is useful to gauge the brittleness, flexibility and elasticity of the films during formulation. Figure 1 shows the strength recorded before the gel film was deformed for different formulation blends encompassing three types of gums at various concentrations $(0.2 \%$, $0.3 \%, 0.4 \%$ and $0.5 \% \mathrm{w} / \mathrm{w})$. Figure 2 depicts the elongation at break for the blends but also at the same concentrations from $0.2 \%$ to $0.5 \%$ (w/w). The highest breaking force recorded for a gel formulated with optimised blends of 1:1:0.5 ratio of carrageenan, LBG and GG was $588 \mathrm{~N}$, while the highest elongation at break was $6.74 \mathrm{~mm}$. The characterisation in terms of strength and elongation at break correspondingly showed that at an optimised ratio of 1:1:0.5 ratio of carrageenan, LBG and GG with concentration of $0.5 \%(\mathrm{w} / \mathrm{w})$ has significantly higher values $(\mathrm{p}<$ $0.05)$ than other concentrations and ratios.

The influence of GG, potassium citrate and glycerine on the tensile strength and elongation at break was also studied and are shown in Figures 3, 4 and 5, respectively. Although the strength increases with the higher amount of GG and potassium citrate, the flexibility of the gel decreases as shown by decreasing elongation at break values. The increment of strength can perhaps be attributed to the fact that GG helped to emulsify vitamin $\mathrm{E}$ into 


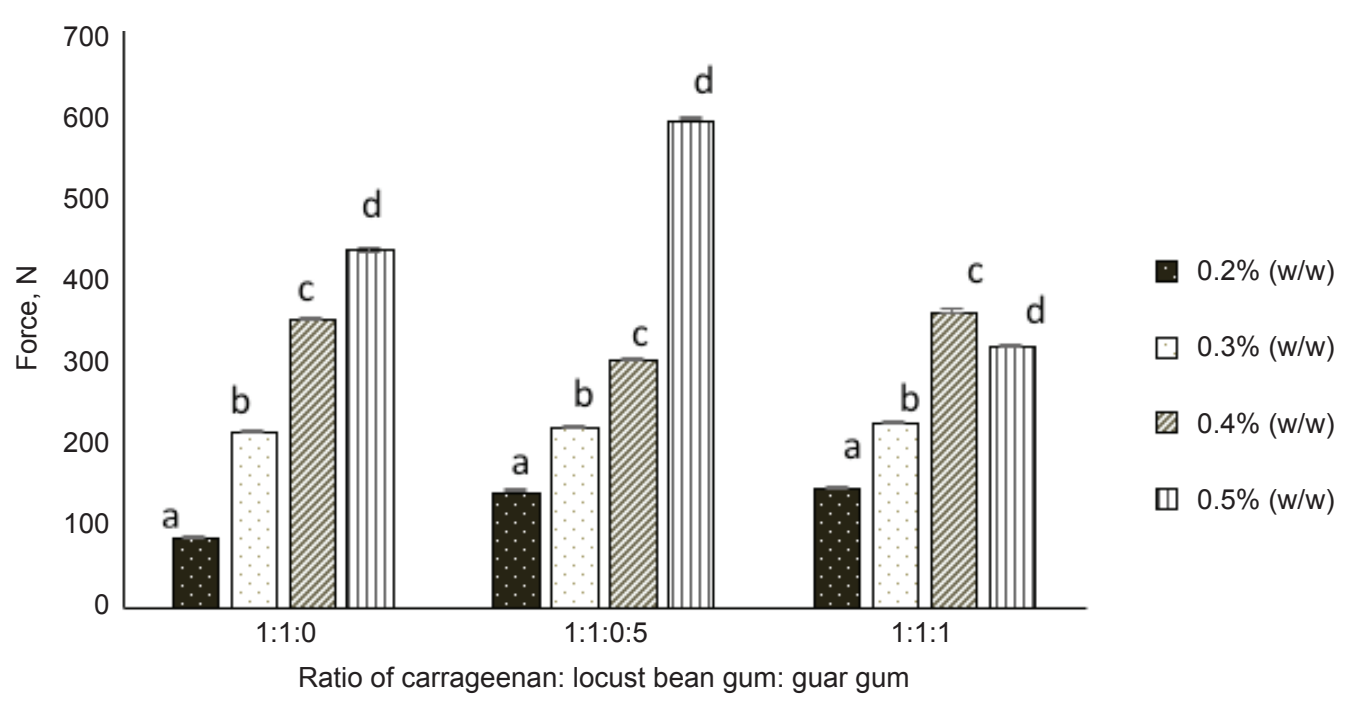

Figure 1. The force needed to initiate gel burst for various ratio of different gums and concentrations. Data as presented as mean $\pm S D(n=3)$. Different alphabets $(a-d)$ within the same ratio of gum indicate significant difference $(p<0.05)$ according to analysis of variance $($ ANOVA) and Tukey tests.

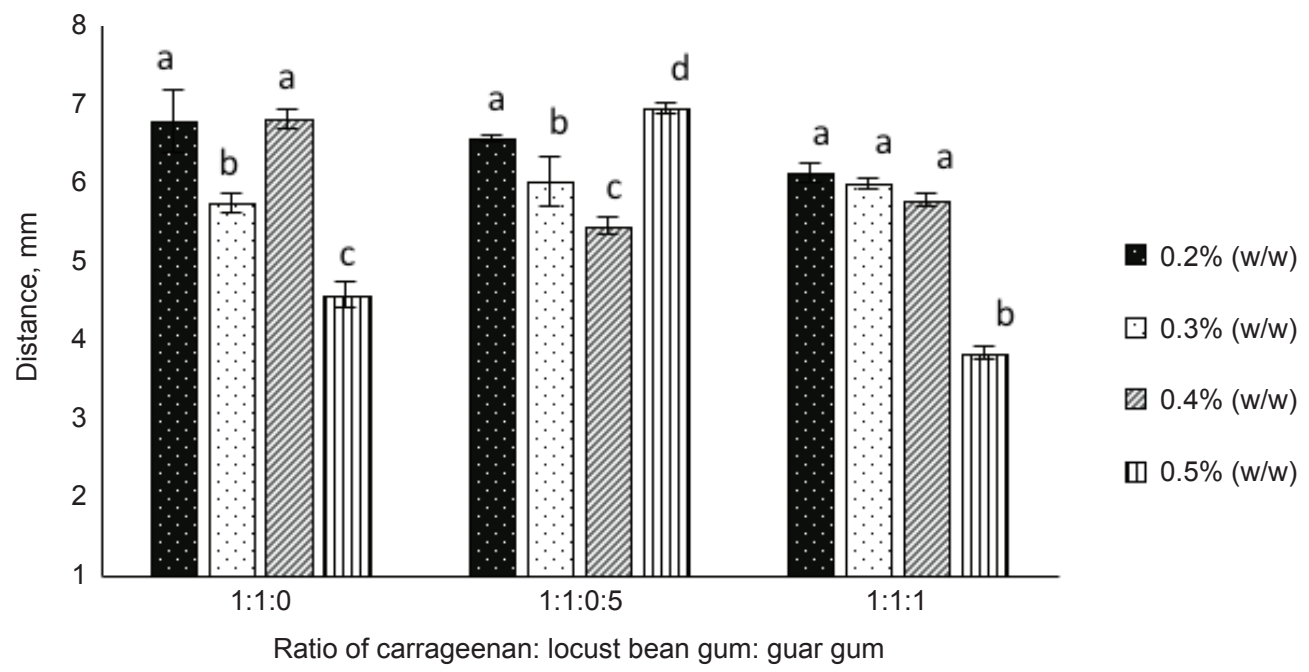

Figure 2. The elongation needed to initiate gel burst for various ratio of different gums and concentrations. Data as presented as mean $\pm S D(n=3)$. Different alphabets $(a-d)$ within the same ratio of gum indicate significant difference $(p<0.05)$ according to analysis of variance $($ ANOVA) and Tukey tests.

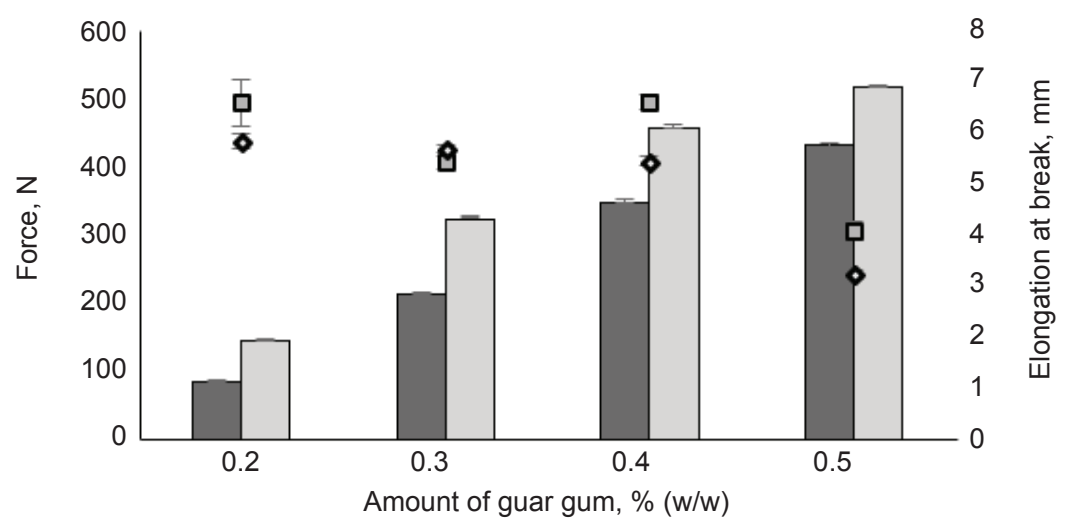

$\square$ Strength without guar gum $\quad \square$ Strength with guar gum

$\square$ Elongation without guar gum $\diamond$ Elongation with guar gum

Figure 3. The force and elongation needed to initiate gel burst for various percentage of guar gum (GG).

Data as presented as mean $\pm S D(n=3)$. 


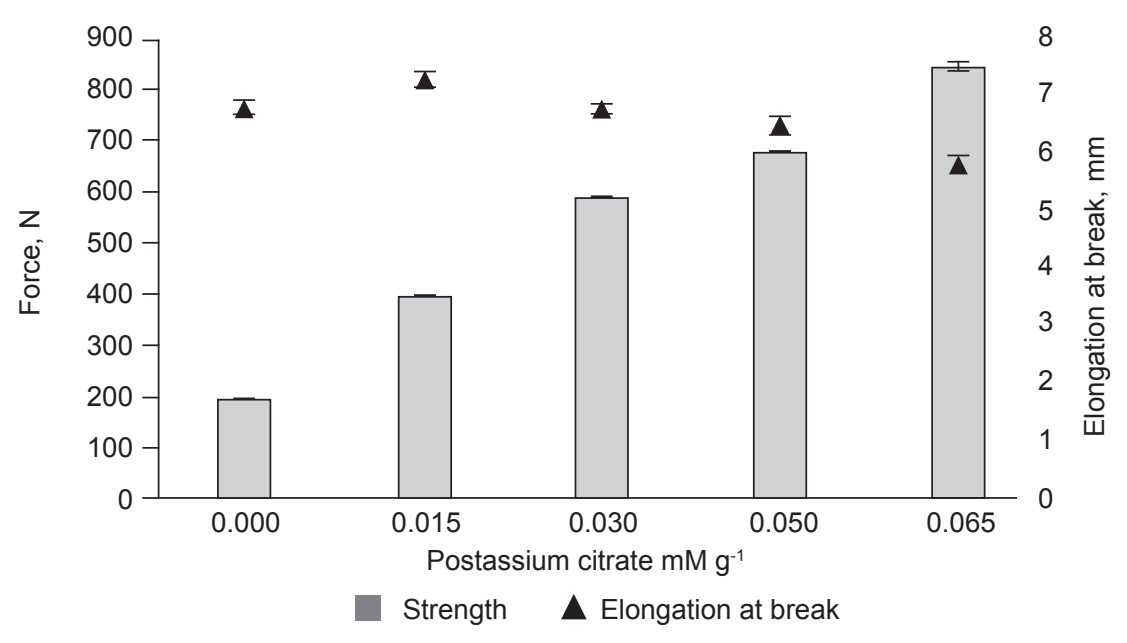

Figure 4. The force and elongation needed to initiate gel burst for various percentage of potassium citrate. Data as presented as mean $\pm S D(n=3)$.

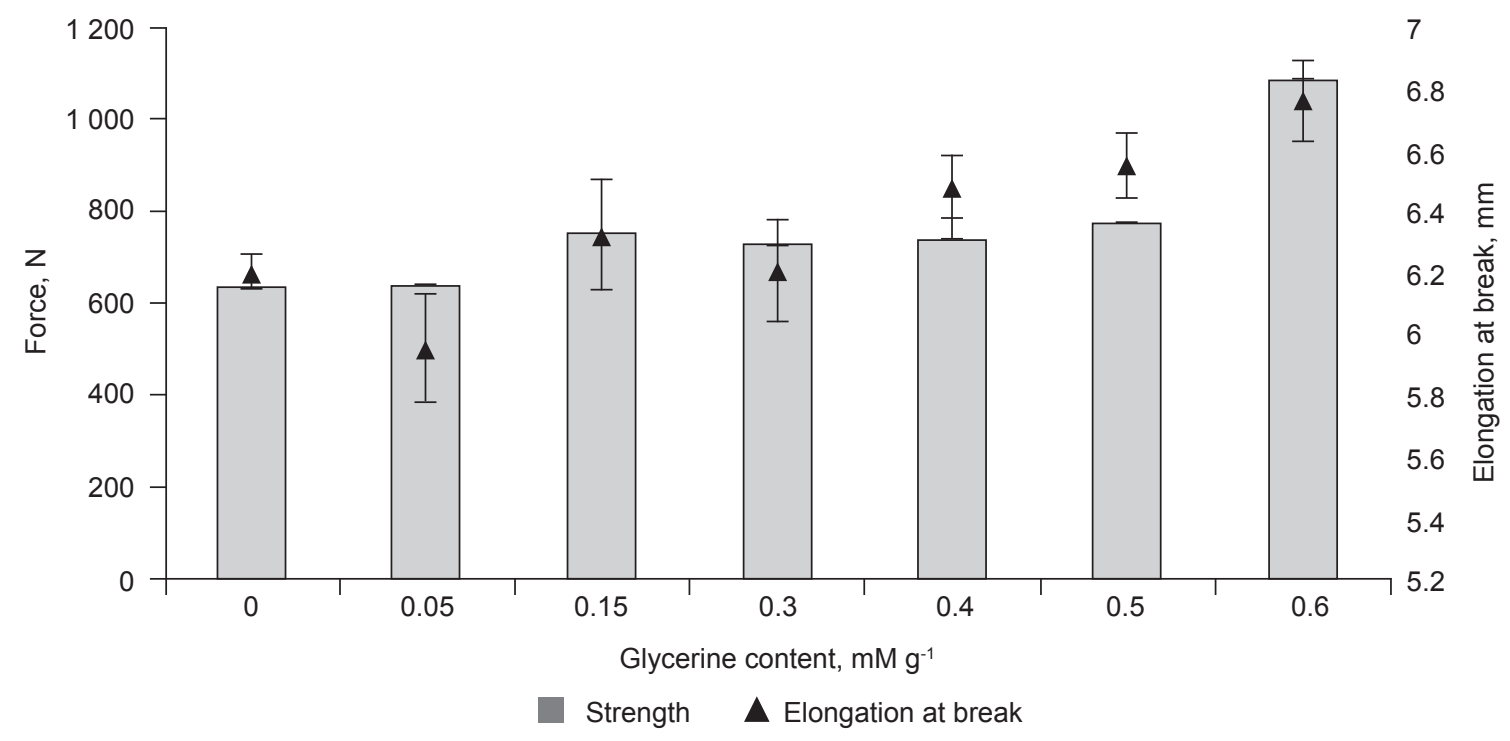

Figure 5. The force and elongation needed to initiate gel burst for various percentage of glycerine. Data as presented as mean $\pm S D$ ( $n=3$ ).

the aqueous system as it has more galactose branch points than LBG, thus helping in setting a more homogenous and uniform network (Tripathy and Das, 2013). Potassium citrate also strengthens the gel with its potassium ions which can fit into the carrageenan helix to stabilise through its negatively charged sulphate groups and positively charged ions within the molecule (Imeson, 2000). While the strength increases, the gel becomes more brittle and less flexible. However, the higher quantity of glycerine has a favourable effect on the gel, likewise on the strength and elongation at break. The use of glycerine as a plasticiser not only increases flexibility and reduces brittleness, but also gives a higher water permeability. Glycerine and water act together to promote the softness and flexibility of the gel and to prevent drying out (humectant). The good plasticiser effect was due to the low volatility, non-crystallinity, hygroscopicity, molecular size and structure of plasticiser relative to the molecular structure and the space lattice of the carrageenan (Cherian et al., 1995).

Two important characteristics of a hydrogel are water holding capacity and permeability. Upon contact with water, the primary bound water is first formed due to the presence of polar hydrophilic groups in the carrageenan. During swelling, the hydrophobic groups will be exposed resulting in further interaction with water molecules within the swelled gel network. The formation of secondary bound water or hydrophobically-bound water ensued. The total bound water is a combination of primary and secondary bound water. Due to the osmotic driving force of the network chains trending towards infinite dilution, the network will absorb additional water. The hydration of the hydrogel continues until an equilibrium swelling level is reached. The additional absorbed water from swelling which is called free water or bulk water fills the space of macropores or voids 
between the network chains, and/or the centre of larger pores. Subsequently dissolution and/ or disintegration process will begin if the network chain or cross-links are composed of degradable material, depending on the composition and nature of the hydrogel. These so called labile bonds can be found in the cross-links or in the polymer backbone that constituted the hydrogel. Under physiological conditions namely enzymatically, chemically or hydrolysis as commonly occurred will cause these bonds to break. Biodegradable hydrogels are therefore advantageous in terms of their properties and behaviour in applications such as a medium for drug delivery via diffusion, wound healing dressing and tissue engineering (Hennink and Nostrum, 2002; Hoffman, 2002).

The TGA profiles of the hydrogel sheets with and without glycerine are shown in Figures $6 a$ and $6 b$ respectively. The pyrolysis of formulated hydrogel sheet occurred in three stages of decomposition as shown in Figure $6 b$. The pyrolysis step and its result indicated significant differences in pyrolysis

(a)

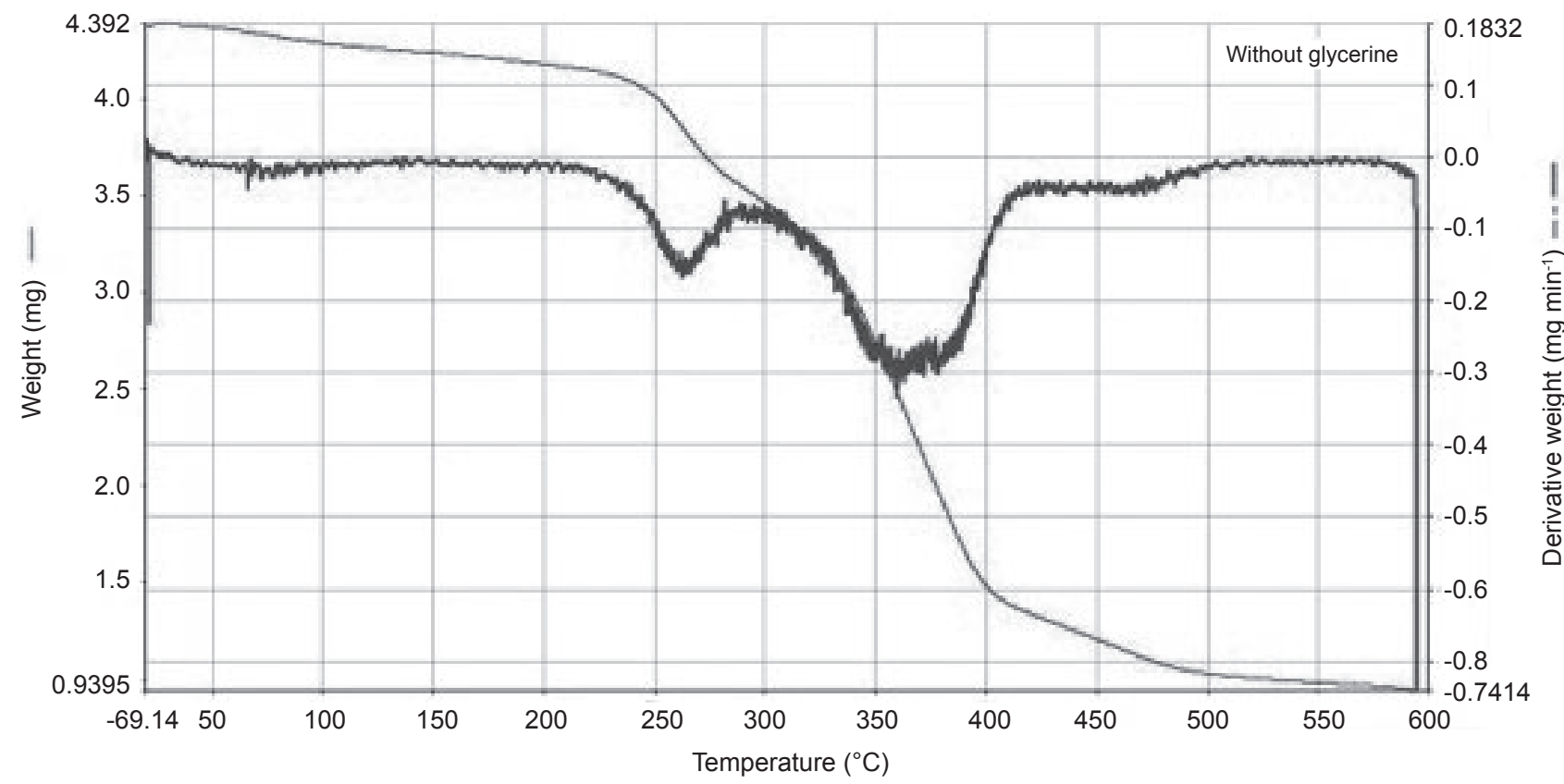

(b)

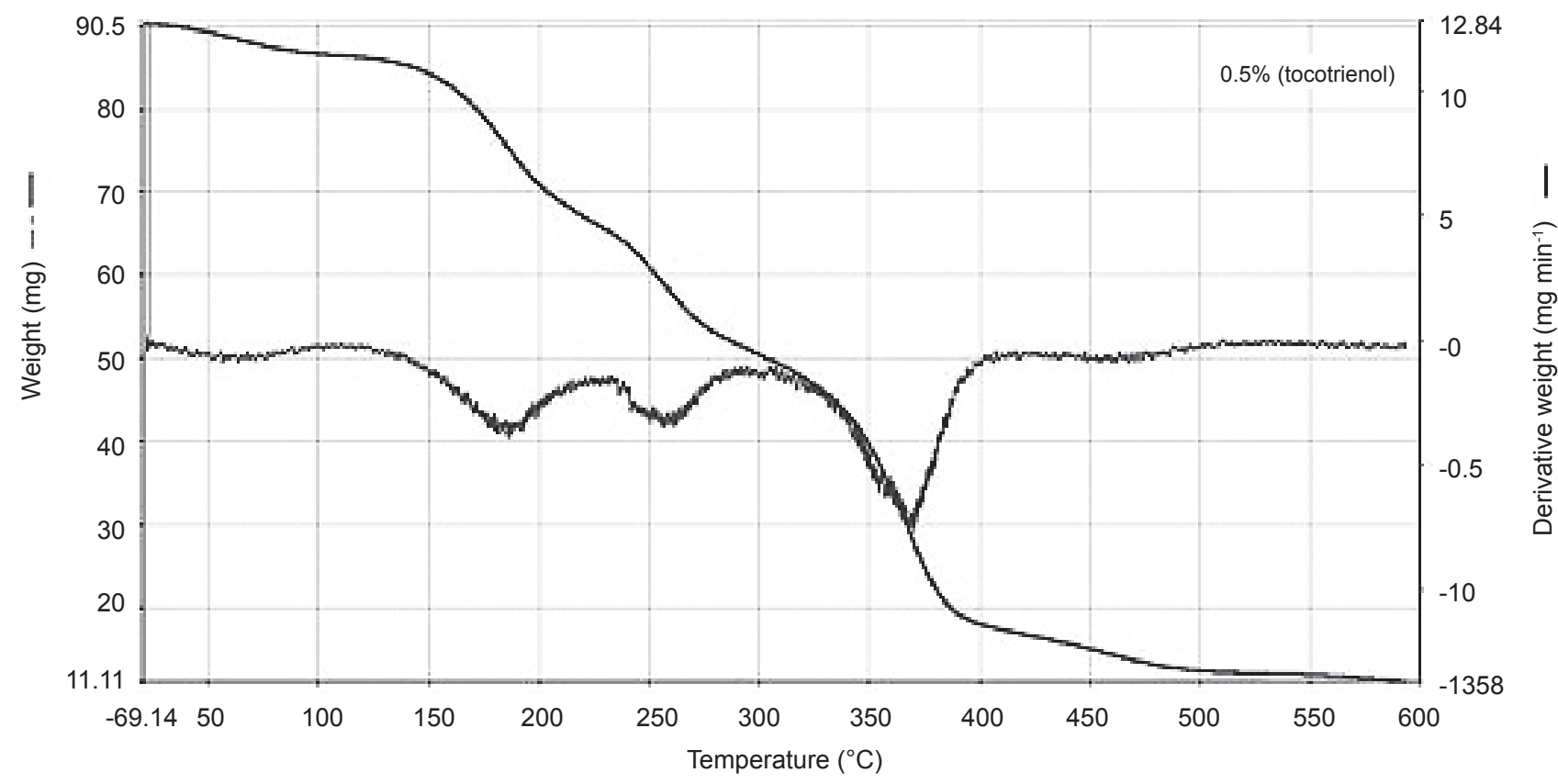

Figure 6. Thermogravimetric analysis (TGA) profiles of the gel sheet (a) without glycerine (b) with $0.4 \mathrm{mM} \mathrm{g}^{-1}$ glycerine. 
behaviour when TGA analyses were performed in nitrogen. During pyrolysis, the biochemical composition corresponded with the stepwise process. The evaporation of water below $110^{\circ} \mathrm{C}$ is indicated in the first peak. There is a lack of moisture peak in Figure $6 a$ indicating lack of secondary bound water in the dried hydrogel sheet sample. The evaporation of other volatile compounds (including glycerine) occurred between $110^{\circ} \mathrm{C}$ and $220^{\circ} \mathrm{C}$ (Cherian et al., 1995). The first lignocellulosic material thermal degradation occurred between $200^{\circ} \mathrm{C}$ and $270^{\circ} \mathrm{C}$ which is attributed to the breakdown of cellulose and the decomposition of hemicellulose. The degradation of lignin is linked to the second step while the final phase which occurred between $270^{\circ} \mathrm{C}$ and $370^{\circ} \mathrm{C}$ is the degradation of cellulose. Macroalgea which carrageenan is derived from, showed a stepwise mass loss where the decomposition of carbohydrate happened from $180^{\circ} \mathrm{C}$ to $270^{\circ} \mathrm{C}$ while degradation of protein occurred from $320^{\circ} \mathrm{C}$ to $450^{\circ} \mathrm{C}$. Volatile metal loss and carbonate decomposition contributed a gradual mass loss above $500^{\circ} \mathrm{C}$. At temperature of $750^{\circ} \mathrm{C}$ to $800^{\circ} \mathrm{C}$, TGA-pyrolysis shows decomposition of inorganic material, probably a consequence of metal carbonates in significant proportion (Ross et al., 2008). When glycerine is used as plasticiser in gel, the TGA thermogram showed the residual water content was considerably higher than gels without glycerine. Glycerine is a well-known hygroscopic material that can retain more water in the gel matrix (Cherian et al., 1995).

Water is primarily used as dispersing medium or plasticiser in processing of the two starches; LBG and GG in the system. Some water interacts directly or indirectly with starch in the starch-water system. As a result, some water has detectable property differences from bulk phase water. Water molecules are strongly bound with hydrophilic groups, mainly hydroxyl groups in the polysaccharides molecules via hydrogen bonding, electrostatic interaction and divalent cationic bridge (Yudianti et al., 2009). At sub-freezing temperature, there is water that remains unfrozen which Roos (1995) called them unfrozen water or bound water. These strongly bound water, or designated as non-freezing water, has different molecular motion from that of pure water (Hatakeyama and Hatakeyama, 1998). The number of non-freezing water molecules is closely related to the number of hydrophilic groups of polysaccharides. The amount of free water which is retained by cross linking networks is larger than non-freezing water. In addition to free and nonfreezing water, there is a portion of water showing intermediate properties whereby possessing lower crystallisation and melting temperatures than pure water (Naoi et al., 2002).

The intermolecular hydrogen bonds which bounded with hydrophilic sites to form nonfreezable water will be disrupted by water upon absorption of it. They were distributed uniformly into the whole network but with restricted mobility. Beyond a certain water content threshold, the absorbed water molecules relegated to the second hydration layer. Due to their location, the absorbed water molecules become freezable, but with a melting point lower than $0^{\circ} \mathrm{C}$. At higher water contents, the bulk-like water which can be frozen at $0^{\circ} \mathrm{C}$ appears and the two kinds of freezable water mentioned above finally amalgamate together at very high water level (Ping et al., 2001).

Elucidation of the hydrogel on the water state, effects of glycerine content on glass transition temperature, melting peak enthalpy, water melting peak, estimation of non-freezable and freezable water were analysed at the glycerine content of 0.00 , $0.05,0.15,0.30,0.40,0.50$ and $0.60 \mathrm{mM} \mathrm{g}^{-1}$ as tabulated in Table 2. It was observed that the melting peak enthalpy $\left(\Delta \mathrm{H}_{\mathrm{m}}\right)$ and water melting peak temperature decreased with increment of glycerine content. The water melting peak temperature hovered between $-16.46^{\circ} \mathrm{C}$ and $-14.11^{\circ} \mathrm{C}$ at 0 to $0.50 \mathrm{mM} \mathrm{g}^{-1}$ before dropping to $-18.87^{\circ} \mathrm{C}$ at $0.60 \mathrm{mM} \mathrm{g}^{-1}$ glycerine. In the hydrogel, the absorbed water gave different distribution in water state with approximately $0.84 \%-1.41 \%$ as freezable water and $98.64 \%$ $99.16 \%$ non-freezable water. The thermograms for all the formulations assayed in this work, show the characteristic water melting peak between $-14.11^{\circ} \mathrm{C}$ and $-18.87^{\circ} \mathrm{C}$ and above $65^{\circ} \mathrm{C}$, there was noticeable

TABLE 2. EFFECT OF THE GLYCERINE CONTENT ON THE GLASS TRANSITION TEMPERATURE, MELTING PEAK ENTHALPY, WATER MELTING PEAK, FREEZING AND NON-FREEZING WATER CONTENT

\begin{tabular}{|c|c|c|c|c|c|c|c|}
\hline Glycerine content, $\left(\mathrm{mM} \mathrm{g}^{-1}\right)$ & 0.00 & 0.05 & 0.15 & 0.30 & 0.40 & 0.50 & 0.60 \\
\hline Glass transition temperature, $\left({ }^{\circ} \mathrm{C}\right)$ & 103.0 & 102.5 & 102.0 & 101.1 & 99.9 & 99.0 & 80.5 \\
\hline Melting peak enthalpy, $\Delta \mathrm{H}_{\mathrm{m}^{\prime}}\left(\mathrm{J} \mathrm{g}^{-1}\right)$ & 297.69 & 300.83 & 258.42 & 253.62 & 208.28 & 232.52 & 175.02 \\
\hline Water melting peak, $\left({ }^{\circ} \mathrm{C}\right)$ & -16.46 & -14.11 & -15.82 & -16.6 & -16.27 & -15.48 & -18.87 \\
\hline Total water content, $\mathrm{W}_{\mathrm{c}}\left(\mathrm{g} \mathrm{g}^{-1}\right)$ & 10.43 & 9.81 & 8.76 & 7.89 & 7.16 & 6.55 & 6.02 \\
\hline Freezing water, $W_{f}\left(\mathrm{~g} \mathrm{~g}^{-1}\right)$ & 0.14 & 0.14 & 0.10 & 0.10 & 0.08 & 0.08 & 0.05 \\
\hline Non-freezing water, $W_{n f}\left(g^{-1}\right)$ & 10.29 & 9.67 & 8.65 & 7.79 & 7.09 & 6.46 & 5.97 \\
\hline$\%$ Of freezing water & 1.36 & 1.41 & 1.19 & 1.29 & 1.06 & 1.27 & 0.84 \\
\hline$\%$ Non-freezing water & 98.64 & 98.59 & 98.81 & 98.71 & 98.94 & 98.73 & 99.16 \\
\hline
\end{tabular}


starch gelatinisation transition (Larrosa et al., 2012).

The addition of hydrocolloids and glycerine in the formula enriched the gel with polyelectrolytes and hydroxyl group. Generally, in the hydrogel network, the hydrophilic group contents determine the amount of bound water (Hatakeyama et al., 2006; Qu et al., 2000). The properties of mixture of these solutes and water were altered in both constituents. Hydrophilic groups cause changes in the mobility of adjacent water, structure and reactivity. The mobility of water was hindered by the presence of ionic groups and ions of organic molecules which work by inducing longer time in evaporation, binding onto the free water and help to control moisture migration. These substances also tend to decrease the frozen water content and lower the water melting enthalpy (Larrosa et al., 2012). Amongst other important properties that changed are water binding activity and viscosity (including thickening and gelling) but also significantly altering many others including prevention of ice recrystallisation, emulsion stabilisation, and organoleptic properties. It may be elucidated that hygroscopic properties of glycerine provided strong hydration of polysaccharides contained within the gel by impeding the evaporation. A sufficient increase in non-freezable water that will eventually reach almost saturated value occurred when glycerine content is increased. A part of water began to crystallise when glycerine content reached above this critical point of saturation. Subsequently, the quantity of freezable water will be reduced with the high formation of crystals.
The glass-rubber transition temperature $(\mathrm{Tg})$ is dependent on the polymer chain elasticity and related to the swelling of hydrogels in the network. The DSC was conducted also to investigate the behaviour of cross-linked swelled hydrogels and the typical thermogram is shown in Figure 7. During the heating process, an endothermic broad peak appeared as a result of gel to sol transition. The glass transition temperature of hydrogel decreased with increasing amount of glycerine. The inclusion of $0.60 \mathrm{mM} \mathrm{g}^{-1}$ of glycerine in the gel can lower the glass transition temperature to $80.5^{\circ} \mathrm{C}$. Thus, the molecules require less energy to transform from glassy to rubbery state when the glycerine content is increased. All cross-linked hydrogel showed an additional sub peak which may be due to incomplete homogeneous network structure of hydrogels. There are many variable features of carrageenan helices with various sizes, junction zones, arrangement and defects that might be present in the network (Iijima et al., 2007; Daniel-da-Silva et al., 2011). The endothermic peak temperature $\left(\mathrm{T}_{\mathrm{p}}\right)$ was seen at $117.6^{\circ} \mathrm{C}, 114.4^{\circ} \mathrm{C}, 109.7^{\circ} \mathrm{C}, 111.8^{\circ} \mathrm{C}, 107.7^{\circ} \mathrm{C}, 118.8^{\circ} \mathrm{C}$ and $109.6^{\circ} \mathrm{C}$. The lowering of the $\mathrm{T}_{\mathrm{p}}$ with the increasing amount of glycerin in the hydrogel is due to the chemical modifications and morphological caused by glycerine. The morphological changes are dependent on the degree of crystallinity formed and the thickness of the crystallites (Yang et al., 2008).

The definition of irritation is the production of reversible damage to the skin following the application of a test substance for up to $4 \mathrm{hr}$, therefore the stronger the irritancy effect, the more

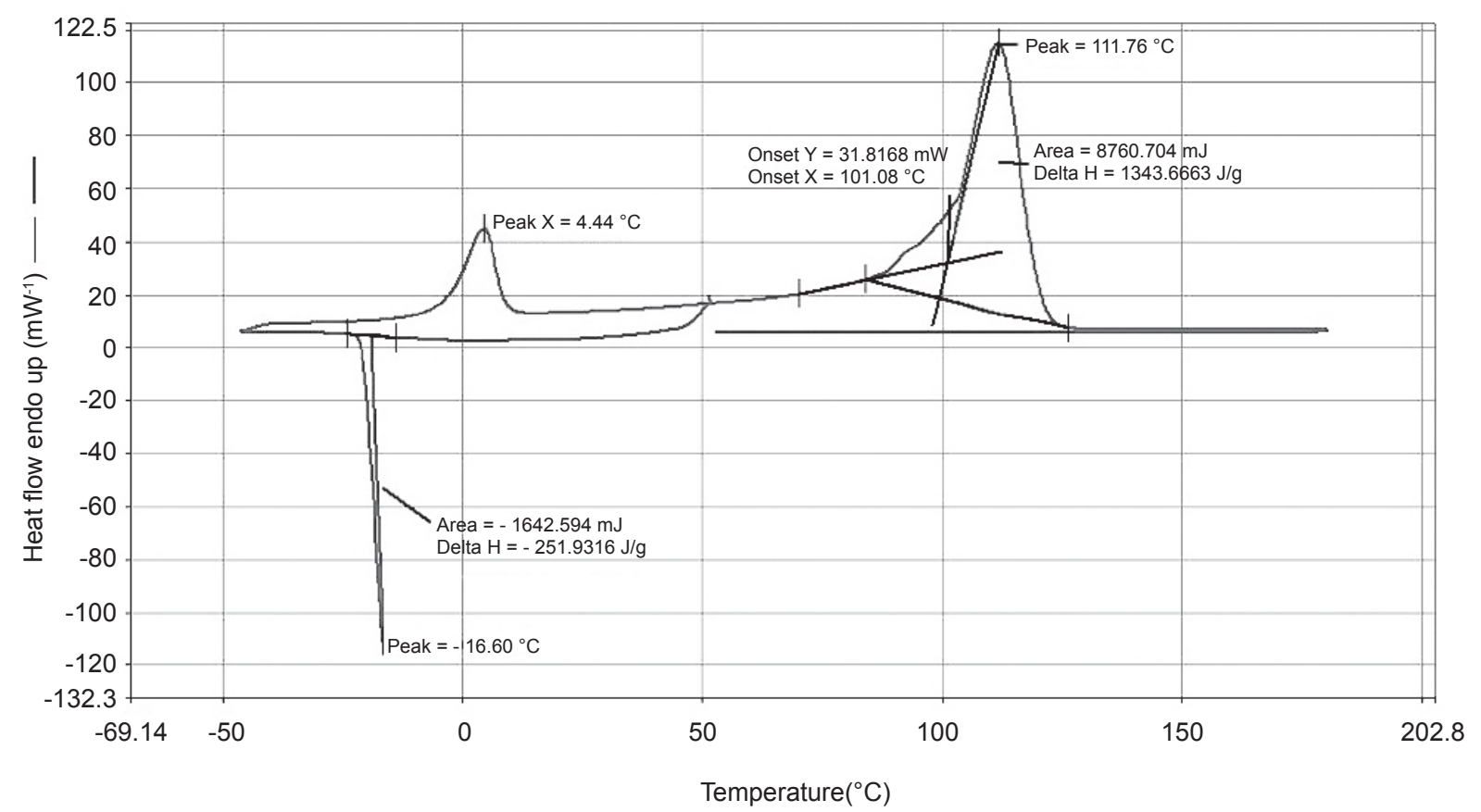

Figure 7. A typical differential scanning calorimetry (DSC) cooling and heating curve of the gel sheet incorporated with glycerine. 
significant the initial injury (cell death) (UNECE, 2011). Irritability assay with Episkin ${ }^{\mathrm{TM}}$ was performed as an alternative in vitro method efficient in prediction of epidermal alterations in vivo caused by irritants. Data generated from the cell viability of in vitro assays with reconstituted human epidermis are shown in Table 3. The method discerns irritant chemicals by identifying their ability to reduce cell viability below defined threshold level of $50 \%$. The epidermis viability, measured as optical density at $570 \mathrm{~nm}$ by the MTT assay and calculated as percentage of cytotoxicity compared to the negative control (PBS), where in the positive control (SDS) it was $1.91 \pm 0.96 \%$. The gels do not irritate when used topically, even with additional use of PEG-40
TABLE 3. VIABILITY OF EPISKIN ${ }^{\mathrm{TM}}$ TISSUES AFTER EXPOSURE (for $42 \mathrm{~min}$ ) TO CONTROL AND GEL

\begin{tabular}{ll}
\hline Sample & Viability (\%) \\
\hline $\begin{array}{l}\text { Gel with PEG-40 hydrogenated } \\
\quad \text { castor oil mixture }\end{array}$ & $93.77 \pm 2.18^{\mathrm{a}}$ \\
$\begin{array}{l}\text { Gel without PEG-40 hydrogenated } \\
\quad \text { castor oil mixture }\end{array}$ & $101.57 \pm 5.18^{\mathrm{a}}$ \\
$\quad \begin{array}{l}\text { Positive control (SLS) } \\
\text { Negative control (PBS) }\end{array}$ & $1.91 \pm 0.96^{\mathrm{b}}$ \\
\hline
\end{tabular}

Note: Cell viability was assessed by MTT assay. Values are expressed as mean $\pm S D(n=3)$. Values in the same column followed by different letters indicate significant differences $(\mathrm{p}<0.05)$.

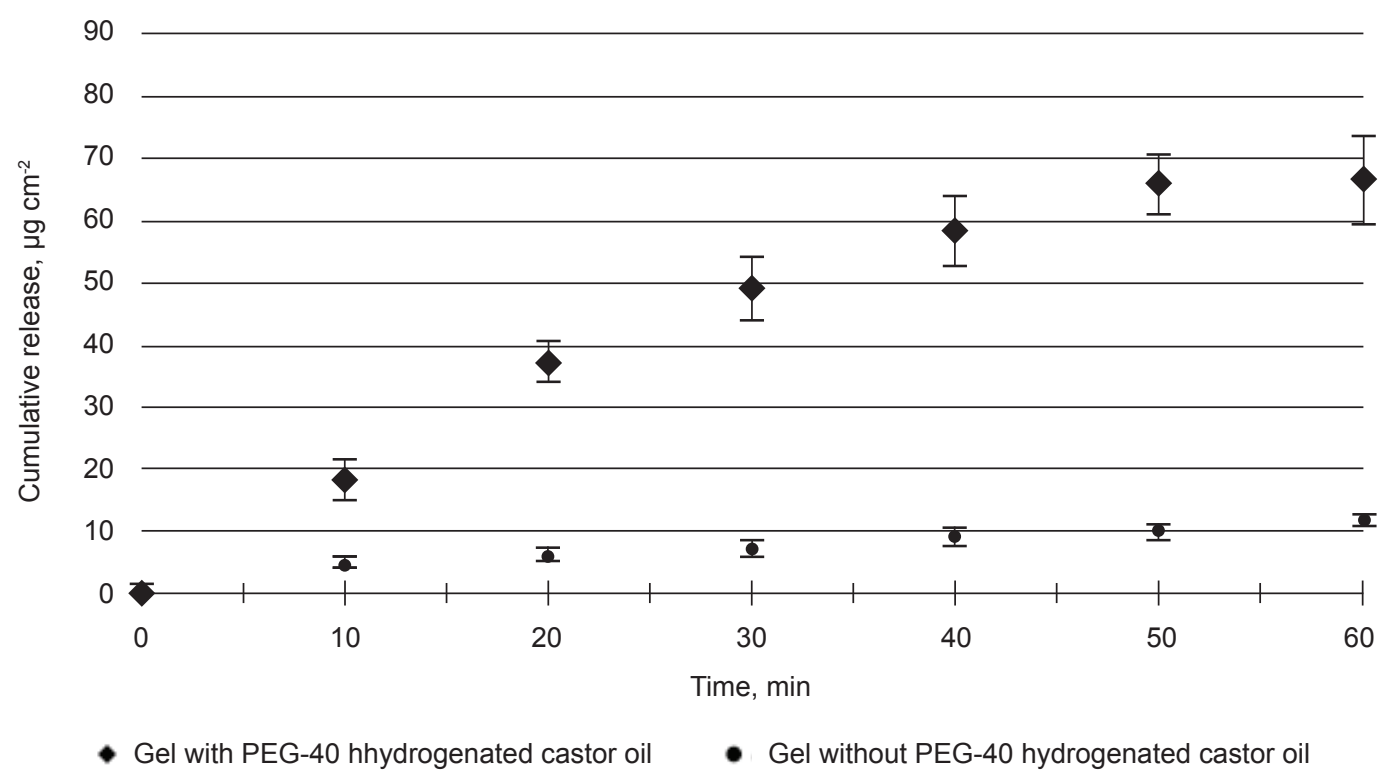

Figure 8. Permeation of tocotrienol-rich palm-based vitamin E (TRPE) ( $\left.\mu \mathrm{g} \mathrm{cm}^{-2}\right)$ through the skin as function of time. Data are presented as mean $\pm S D(n=3)$.

hydrogenated castor oil mixture as solubiliser as the viability is higher than $50 \%$, with value of $93.77 \pm$ $2.18 \%$.

Results of TRPE permeation experiments are illustrated in Figure 8 which shows that the inclusion of PEG-40 hydrogenated castor oil mixture remarkably increased the permeation of TRPE through membrane. However, the permeation parameters $\left(J, t_{L}, Q_{60 \text { min, }}, K_{p}, D_{m}, K_{m}\right)$ as summarised in Table 4 defined the dynamics of the permeation of TRPE with and without solubiliser. The steady state flux of TRPE through membrane was calculated to be $0.63 \pm 0.039 \mu \mathrm{g} \mathrm{cm} \mathrm{cm}^{-2} \mathrm{~min}^{-1}$ after application of gel formulation with PEG-40 hydrogenated castor oil mixture, while the steady state flux of TRPE without solubiliser PEG-40 hydrogenated castor oil decreased about six times with $0.11 \pm 0.02 \mu \mathrm{g}$ $\mathrm{cm}^{-2} \mathrm{~min}^{-1}$. The total amount of TRPE permeated from gel with PEG-40 hydrogenated castor oil was $66.89 \pm 4.13 \mu \mathrm{g} \mathrm{cm}^{-2}$ compared to $11.59 \pm 0.10 \mu \mathrm{g} \mathrm{cm}^{-2}$ obtained from gel without PEG-40 hydrogenated castor oil mixture. In both cases, the differences were statistically significant: $P=0.0375$ in the case of flux; $P=0.008$ for TRPE permeated. The ratelimiting step was due to TRPE hydrophobicity which rendered it insoluble with the water (Monti et al., 2015). The result also indicatively suggested that the PEG-40 hydrogenated castor oil has emulsified the TRPE into finer particles that was suspended in the gel and its fluid.

The influence of $K_{p}, D_{m}$ and $K_{m}$ was investigated to assess the TRPE permeation through the skin 
TABLE 4. PERMEATION PARAMETERS OF TOCOTRIENOL-RICH PALM-BASED VITAMIN E (TRPE) FROM FORMULATIONS OF GEL WITH/WITHOUT PEG-40 HYDROGENATED CASTOR OIL MIXTURE

\begin{tabular}{|c|c|c|c|c|c|c|}
\hline Formulation & $\begin{array}{l}\text { Flux }, J \\
\left(\mu \mathrm{g} \mathrm{cm}^{-2} \mathrm{~min}^{-1}\right)\end{array}$ & $\begin{array}{l}\text { Lag } \\
\text { time, } t_{L} \\
\text { (min) }\end{array}$ & $\begin{array}{l}\text { Cumulative } \\
\text { amount, } Q_{60} \mathrm{~min} \\
\left(\mu \mathrm{g} \mathrm{cm}^{-2}\right)\end{array}$ & 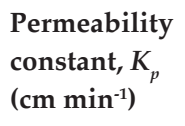 & $\begin{array}{l}\text { Diffusion } \\
\text { coefficient, } D_{m} \\
\left(\mathrm{~cm}^{2} \min ^{-1}\right)\end{array}$ & $\begin{array}{l}\text { Partition } \\
\text { coefficient, } K_{m}\end{array}$ \\
\hline $\begin{array}{l}\text { Gel with PEG-40 } \\
\text { hydrogenated } \\
\text { castor mixture oil }\end{array}$ & $0.63 \pm 0.04$ & 6.17 & $66.89 \pm 4.13$ & $1.26 \times 10^{-5}$ & 5563.34 & $3.28 \times 10^{-7}$ \\
\hline $\begin{array}{l}\text { Gel without PEG-40 } \\
\text { hydrogenated } \\
\text { castor oil mixture }\end{array}$ & $0.11 \pm 0.02$ & 6.67 & $11.59 \pm 0.10$ & $2.18 \times 10^{-6}$ & 32103.69 & $9.86 \times 10^{-9}$ \\
\hline
\end{tabular}

as modelled by the polysulfone membrane. This stemmed from the various interactions between TRPE/gel, gel/membrane and TRPE/membrane. As shown in Table $4, D_{m}$ and $K_{m}$ values showed inverse trend as $D_{m}$ increased whilst $K_{m}$ values fell. As other researchers (Monti et al., 2015) pointed out, data from $D_{m}$ alone could not be regarded as a predictive parameter to evaluate TRPE permeation because the lag time and the condition once the steady state is achieved must be taken into account and considered. The membrane/gel partition coefficient, $K_{m}$ was about 50 -fold higher for the gel with PEG-40 hydrogenated castor oil as solubiliser than for the gel without the solubiliser. Hence, it was noted that the inclusion of PEG-40 hydrogenated castor oil has improved the permeation of TRPE based on polysulfone membrane model.

The average diameter of TRPE that has permeated the PBS is shown in Figure 9. The result

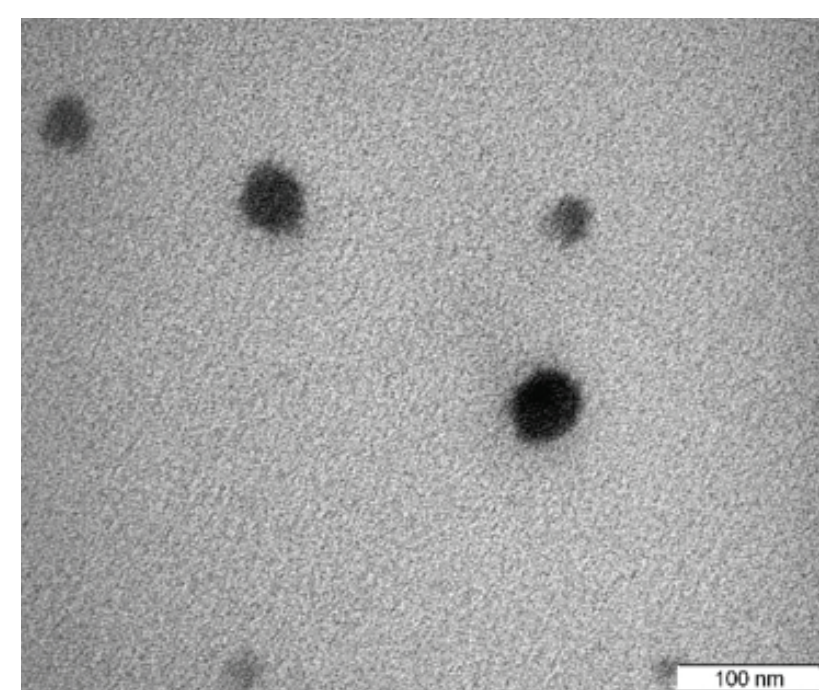

Figure 10. Transmission electron microscopy (TEM) of tocotrienol-rich palm-based vitamin E (TRPE) that has permeate phosphate buffered saline (PBS) in vertical diffusion cell system as magnified 200 000X.

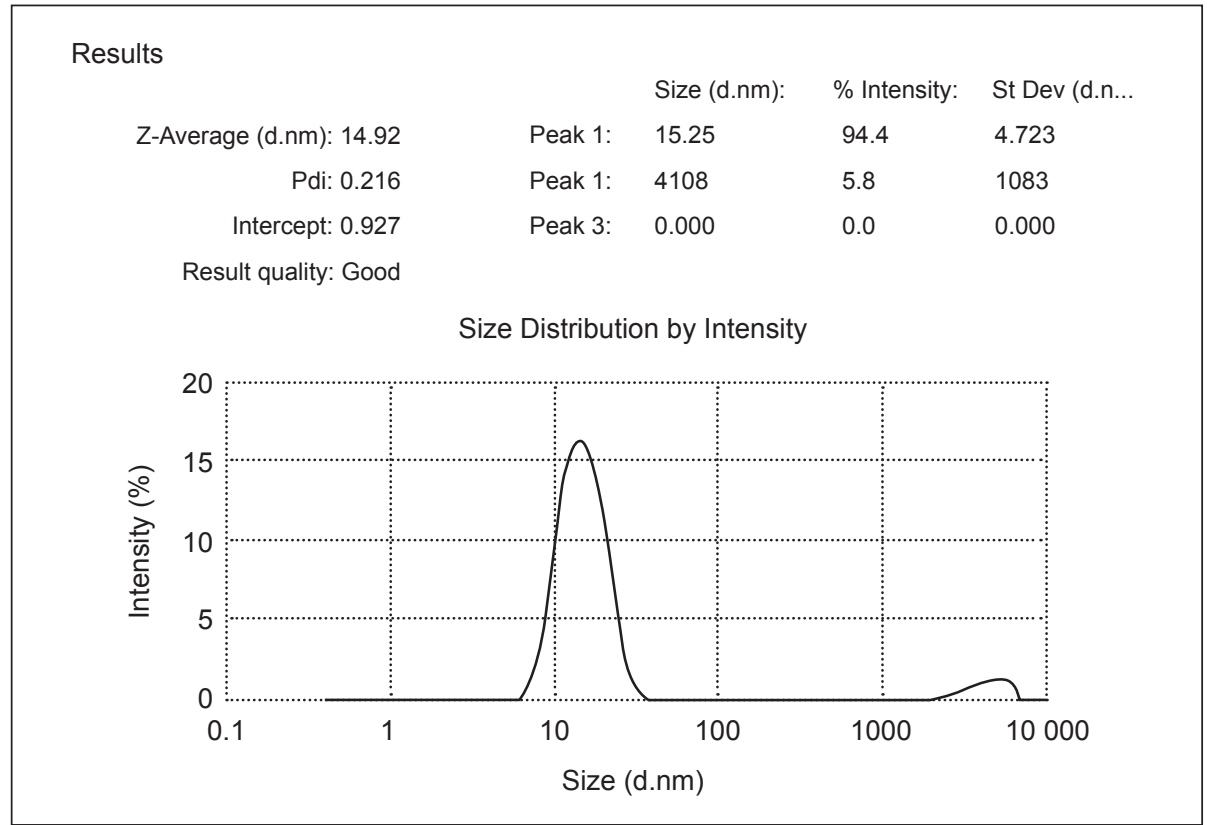

Figure 9. Particle size distribution curve for tocotrienol-rich palm-based vitamin E (TRPE) permeated into phosphate buffered saline (PBS). 
showed that the mean diameter of TRPE droplet was found to be about $14.92 \mathrm{~nm}$ with narrow polydispersity index of 0.216 . As indicated in the TEM, the TRPE droplets were almost spherical in shape as shown in Figure 10.

\section{CONCLUSION}

A unique gel system was successfully prepared and evaluated with the objective to incorporate TRPE, a hydrophobic type of actives. The gel satisfied many criteria in terms of strength, pliability, water type, permeability which were influenced by the additives used such as GG, potassium citrate, glycerine and PEG-40 hydrogenated castor oil mixture. The inclusion of PEG- 40 hydrogenated castor oil has improved the permeation of TRPE based on polysulfone membrane model. The particle size analysis showed that most of the TRPE droplets were about $14.92 \mathrm{~nm}$ with narrow polydispersity index of 0.216 . The TEM revealed that the TRPE droplets were almost spherical in shape. The hydrogel system was able to provide the benefits of TRPE and moisturisation without any potential irritancy. Hence, this hydrogel can be a potential therapeutic mask for skin.

\section{ACKNOWLEDGEMENT}

The authors are grateful to the Director-General of MPOB for permission to publish this article.

\section{REFERENCES}

ANDERSON, J M and LANGONE, J J (1999). Issues and perspectives on the biocompatibility and immunotoxicity evaluation of implanted controlled release systems. J. Controlled Release, 57(2): 107-113. PMID: 9971889 [PubMed - indexed for MEDLINE]

CHERIAN G; GENNADIOS A; WELLER C and CHINACHOTI, P (1995). Thermomechanical behavior of wheat gluten films: effect of sucrose, glycerin and sorbitol. Cereal Chemistry, 72(1): 1-6. http: / / www.aaccnet.org/publications / cc/ backissues / 1995/Documents / 72_1.pdf

CHUDZIKOWSKI, R J (1971). Guar gum and its applications. J. Society of Cosmetic Chemists, 22: 4360. http: / /journal.scconline.org/pdf/cc1971/ cc022n01/p00043-p00060.pdf

DANIEL-DA-SILVA A L; FERREIRA, L; GIL, A M and TRINDADE, T (2011). Synthesis and swelling behavior of temperature responsive $\kappa$-carrageenan nanogels. J. Colloid and Interface Science, 355(2): 512517. DOI: $10.1016 /$ j.jcis.2010.12.071.
DEA, I C M and MORRISSON, A (1975). Chemistry and interaction of seed galactomannans. Advances Carbohydrate Chemistry and Biochemistry, 31: 241-312. DOI: 10.1016/S0065-2318(08)60298-X.

DEAN, J A and LANGE, N A (1973). Lange's Handbook of Chemistry. 11 ${ }^{\text {th }}$ Edn. McGraw-Hill, p. 9.

DEEPA, G; THULASIDASAN, A K T; ANTO, R J; PILLAI, J J and KUMAR, G S V (2012). Cross-linked acrylic hydrogel for the controlled delivery of hydrophobic drugs in cancer therapy, International J. Nanomedicine, 7: 4077-4088. DOI: 10.2147/IJN. S30149.

FARNOOSH, K; ANTONIJEVIC, $\mathrm{M}$ D; CHOWDHRY, B Z and BOATENG, J S (2011). Formulation development of a carrageenan based delivery system using ibuprofen as a model drug. J. Biomaterials and Nanotechnology, 2(5A): 582-595. DOI: 10.4236 / jbnb.2011.225070.

FERNANDES, $\mathrm{P} \mathrm{B}$; GONCALVES, $\mathrm{M} \mathrm{P}$ and DOUBLIER, J L (1991). Phase diagrams in kappacarrageenan/locust bean gum systems. Food Hydrocolloids, 5(1-2): 71-73. DOI: 10.1016/S0268005X(09)80289-0.

GULREZ, S K H; Al-ASSAF, S and PHILLIPS, G O (2011). Hydrogels: methods of preparation, characterization and applications. Progress in Molecular and Environmental Bioengineering - from Analysis and Modeling to Technology Applications. Rijeka, Croatia, InTech Publisher. p. 117-150.

HATAKEYAMA, $\mathrm{H}$ and HATAKEYAMA T (1998). Interaction between water and hydrophilic polymers. Thermochimica Acta, 308(1): 3-22. DOI: 10.1016/S0040-6031(97)00325-0.

HATAKEYAMA, T; UEDA, C and HATAKEYAMA, $H$ (2006). Structural change of water by gelation of curdlan suspension. J. Thermal Analysis and Calorimetry, 85(3): 661-668. DOI: 10.1007/s10973006-7641-z.

HENNINK, W E and NOSTRUM, C F V (2002). Novel crosslinking methods to design hydrogels. Advanced Drug Delivery Reviews, 54: 13. DOI: 10.1016/S0169409X(01)00240-X.

HOFFMAN, A S (2002). Hydrogels for biomedical applications. Advanced Drug Delivery Reviews, 54: 3-12. DOI: 10.1016/S0169-409X(01)00239-3.

IIJIMA, M; HATAKEYAMA, T; TAKAHASHI, $\mathrm{M}$ and HATAKEYAMA H (2007). Effect of thermal history on kappa-carrageenan hydrogelation by differential scanning calorimetry. Thermochimica Acta, 452: 5358. DOI:10.1016/j.tca.2006.10.019. 
IMESON, A P (2000). Carrageenan. Handbook of Hydrocolloids. Woodhead Publishing Limited, CRC Press. p. 87-102.

KILPATRICK-LIVERMAN, L; MATTAI, J; TINSLEY, $\mathrm{R}$ and WU, J (2009). Mechanism of skin hydration. Handbook of Cosmetic Science and Technology. $3^{\text {rd }}$ Edn. Informa Healthcare USA, Inc., New York. p. 91-106.

KIM, I S; JEONG, Y I; KIM, D H; LEE, Y H and SUNG-HO KIM, S H (2001). Albumin release from biodegradable hydrogels composed of dextran and (polyethylene glycol) macromer. Archives of Pharmacal Research. 24: 69-73. PMID: 11235815 [PubMed - indexed for MEDLINE] http://www. ncbi.nlm.nih.gov/pubmed/11235815

LARROSA, V J; LORENZO G; ZARITZKY, N E and CALIFANO, A N (2012). Effect of the addition of proteins and hydrocolloids on the water mobility in gluten-free pasta formulations. Water, 4: 1-17. DOI: 10.14294/WATER.2012.2.

MONTI, D; CHETONI, P; BURGALASSI, S; TAMPUCCI, $\mathrm{M}$; CENTINI, $\mathrm{M}$ and ANSELMI, $\mathrm{C}$ (2015). 4-Methylbenzylidene camphor microspheres: reconstituted epidermis $\left(\right.$ Skinethic ${ }^{\circledR}$ ) permeation and distribution. International J. Cosmetic Science, 37: 298-305. DOI: 10.1111/ics.12199

NAOI, S; HATAKEYAMA, T and HATAKEYAMA, $H$ (2002). Phase transition of locust bean gum-, tara gum- and guar gum-water systems. J. Thermal Analysis and Calorimetry, 70(3): 841-852. DOI: 10.1023 / A:1022260304686.

PING, Z H; NGUYEN, Q T; CHEN, S M; ZHOU, J $Q$ and DING, Y D (2001). States of water in different hydrophilic polymers - DSC and FTIR studies. Polymer, 42(20): 8461-8467. DOI: 10.1016/S00323861(01)00358-5.

QU, X; WIRSEN, A and ALBERTSSON, A C (2000). Novel pH-sensitive chitosan hydrogels: swelling behavior and states of water. Polymer, 41(12): 45894598. DOI: 10.1016/S0032-3861(99)00685-0.

REES, D A (1969). Structure, conformation and mechanism in the formation of polysaccharides gels and networks. Advances in Carbohydrate Chemistry and Biochemistry, 24: 267-332. PMID: 4913938 [PubMed - indexed for MEDLINE]
ROOS, Y H (1995). Phase transitions and unfreezable water content of carrot, reindeer meat and white bread studies using differential scanning calorimetry. J. Food Science, 51(3): 684-686. DOI: 10.1111/j.13652621.1986.tb13911.x.

ROSIAK, J M and YOSHII, F (1999). Hydrogels and their medical applications. Nuclear Instruments and Methods in Physics Research, 151(1-4): 56-64. DOI: 10.1016/S0168-583X(99)00118-4.

ROSS, A B; JONES, J M; KUBACKI, M L; BRIDGEMAN, T (2008). Classification of macroalgae as fuel and its thermochemical behavior. Bioresource Technology, 99: 6494-6504. DOI: 10.1016/j. biortech.2007.11.036.

SMETANA, K (1993). Cell biology of hydrogels. Biomaterials, 14(14): 1046-1050. DOI: 10.1016/01429612(93)90203-E.

TRIPATHY, S and DAS, M K (2013). Guar gum: present status and applications. J. Pharmaceutical and Scientific Innovation, 2(4): 24-28. DOI: $10.7897 / 2277-$ 4572.02447.

TSUJIHATA, S (2010). Gel sheet and cosmetic preparation in sheet form using the same. United States patent No. US 2010 / 0239621A1. https: / / docs. google.com/viewer?url=patentimages.storage googleapis.com/pdfs / US20100239621.pdf

UNECE (2011). Skin corrosion/irritation. Globally Harmonized System of Classification and Labelling of Chemicals (GHS). $4^{\text {th }}$ Edn. United Nations Department of Labor, New York, Geneva.

YANG, X; ZHU Z; LIU, Q; CHEN, X and MAA, M (2008). Effects of PVA, agar contents, and irradiation doses on properties of PVA/ws-chitosan/glycerol hydrogels made by g-irradiation followed by freezethawing. Radiation Physics and Chemistry, 77(8): 954960. DOI: 10.1016/j.radphyschem.2008.02.011.

YUDIANTI, R; KARIN, M; SAKAMOTO, M and AZUMA, J (2009). DSC analysis on water state of salvia hydrogels. Macromolecular Research, 17(12): 1015-1020. DOI: 10.1007/BF03218650.

ZAFARIZAL ALDRIN AZIZUL HASAN; ROSNAH ISMAIL and SALMIAH AHMAD (2008). Does the palm tocotrienol-rich fraction induce irritant contact dermatitis? J. Oil Palm Res. Vol. 20(1): 508-515. 